\title{
CONFRONTOS: A HOMOAFETIVIDADE E A hegemonia em Pela NoIte (1983), De CAIO FERNANDO ABREU
}

\section{CONFLICTS: HOMOAFFECTION AND HEGEMONY IN Pela Noite (1983), by Caio Fernando Abreu}

\author{
Karine Passeri* \\ Silvio Ruiz Paradiso**
}

Resumo: A literatura homoerótica e a teoria queer analisam a sexualidade e o desejo nas relações sociais, principalmente a respeito do homossexual. Na novela Pela Noite (1983), de Caio Fernando Abreu, percebemos essa temática homoerótica. com base nesse tema, analisaremos o comportamento dos personagens quando estão em ambiente de público gay e quando estão em espaço predominantemente heterossexual; além disso, abordaremos também os momentos em que um dos personagens se encontra com o seguinte questionamento: é possível ou não haver amor entre dois homens? Diante disso, objetivamos estudar a influência da ideologia da sociedade machista e patriarcal na vida e no comportamento dos personagens. Como resultado, esperamos que os personagens, por estarem tão alienados em relação às "leis" sociais vigentes, se submetam inconscientemente a elas e por isso apresentem dificuldade a respeito de como se comportar em determinados espaços e sobre como amar outros homens.

Palavras-chave: Literatura homoerótica. Homoerotismo. Sociedade. Hegemonia.

ABSTRACT: Homoerotic literature and queer theory analyze sexuality and desire in social relations, especially homosexuality. In the novel Pela Noite (1983) by Caio Fernando Abreu, the homoerotic theme can be observed. Based on this theme, this article analyzes the behavior of characters in the novel when they are in a gay environment and when they are in a predominantly heterosexual space; in addition, the article analyzes the moments when one of the characters asks himself: "is it possible or not to exist love between two men?" Therefore, this study focuses on the influence of ideology in a patriarchal and sexist society in the life and behavior of the

\footnotetext{
* Graduada em Letras português/inglês pelo Centro Universitário de Maringá. E-mail: <karinepasseri@hotmail.com>.

** Doutorando em Estudos Literários pela Universidade Estadual de Londrina (UEL). Especialista em Religião e Religiosidades nas literaturas pós-coloniais. E-mail:<silvinhoparadiso@hotmail.com>.
} 
characters. As a result, it is expected that the characters that are so alienated with the social "laws", unconsciously submit to them and they demonstrate difficulties in behaving in certain spaces and knowing how to love other men.

KEYwords: Homoerotic literature. Homoeroticism. Society. Hegemony.

\section{INTRODUÇÃo}

Os Estudos Culturais constituem uma área de pesquisa sobre comunicação e cultura. Seu objetivo principal é estudar a cultura como um campo em que ocorrem lutas entre várias culturas ligadas a determinadas classes sociais; em outras palavras, os Estudos Culturais propõem a análise das práticas culturais de grupos sociais marginalizados, como: a mulher, o negro, o gay, o novo. Dessa forma, pode-se contrastar a cultura do subalterno com a cultura dominante (PARADISO; PELINCER, 2007).

A partir dos Estudos Culturais surgiram os queer studies ou a teoria queer no decênio de 1980, nos Estados Unidos, com o objetivo de analisar a dinâmica da sexualidade e do desejo nas relações sociais, focando a hegemonia como objeto de estudo e análise crítica, pois as estruturas sociais hegemônicas criam sujeitos como normais e naturais e outros perversos ou patológicos (MISKOLCI, 2009).

O termo inglês queer pode ser traduzido por 'estranho', 'esquisito', mas também se constitui na forma pejorativa com que são designados os homens e mulheres homossexuais. Esta expressão foi escolhida pelos teóricos pois caracteriza a intenção de oposição à heteronormatividade, para eles queer significa colocar-se contra a normalização da sexualidade (LOURO, 2001).
Observa-se que essa temática homoerótica ganha mais espaço e mais força no campo literário. Diversos escritores a trabalham em sua obra, como João Gilberto Noll, Bernardo Carvalho e Caio Fernando Abreu, por exemplo.

Consoante o pensamento de Thomé (2009, p. 32), a novela Pela Noite (1983) será considerado como "texto gay", pois seu tema central é o sentimento homoafetivo. Chegamos a tal conclusão porque é sobre isso que os protagonistas - Santiago e Pérsio - discutem a maior parte do tempo; pelo fato dos personagens se assumirem como homossexuais e ainda revelarem suas experiências amorosas passadas; por eles frequentarem locais de público quase exclusivamente gay e, ainda, pelo fato de ao final eles terminarem juntos, o que culmina a relação homoafetiva.

Considerando esse assunto central, torna-se relevante a justificação do uso da nomenclatura homoerotismo ou homoafetividade ao invés de homossexualismo nesse contexto.

De acordo com Costa (1992, p. 11), "homoerotismo é preferível a homossexualidade' ou 'homossexualismo' porque tais palavras remetem quem as emprega ao vocabulário do século XIX". Quando o termo "homossexual" surgiu na língua corrente da época, carregava forte conotação pejorativa, pois o "homossexual" era visto como o 
oposto do ideal masculino que a sociedade burguesa tanto pregava; o uso de tal palavra reproduz, automaticamente, todo o preconceito burguês patriarcal nela embutido (COSTA, 1992, p.24). Por tais razões, será utilizado o termo homoafetividade ou homoerotismo para designar qualquer relação de cunho "homossexual" e, ainda, concorda-se com a seguinte afirmação de Costa (1992, p.21): "homoerotismo é uma noção mais flexível e que descreve melhor a pluralidade das práticas ou desejos dos homens same-sex oriented. [...] exclui toda e qualquer alusão à doença, desvio, anormalidade, perversão".

Em relação à novela, os dois personagens principais - Santiago e Pérsio - são homossexuais e toda a ação da narrativa acontece ao redor deles. Ambos já tiveram relações sexuais com outros homens. Todavia, enquanto Santiago viveu relacionamentos duradouros, todas as relações de Pérsio foram passageiras e superficiais. Assim, observa-se que esse personagem nunca nutriu um sentimento de amor por outro homem e, além disso, mostra-se contra a possibilidade de existir amor e afeto entre dois homens.

Com base nessa contextualização, nosso objetivo será analisar como essa atitude de Pérsio contrária à homoafetividade está ligada ao preconceito social que essa 'minoria' de gênero sofre. Afinal, os homossexuais ocupam um lugar marginalizado e invisível na divisão de classes, isto é, os gays não possuem seus direitos civis porque "não existem" na sociedade, como afirma Foucault (2000, p.16): "os homossexuais não constituem uma classe social”. Este trabalho debaterá esse preconceito, muitas vezes sutil, existente não só entre indivíduos homossexuais, mas também nos ambientes que frequentam.

A minoria homossexual possui, segundo Foucault (2000), essa invisibilidade social, pois a classe dominante não os considera como integrantes do sistema social. Pelo fato de eles terem afinidade com pessoas do mesmo sexo, a hegemonia que é regida segundo os padrões cristãos e patriarcais, os exclui da possibilidade de serem engajados em sociedade e reconhecidos como cidadãos que possuem uma comunidade e uma identidade.

Para entendermos melhor que o preconceito é fruto de um sistema social cristão e patriarcal, o qual rege indiretamente as atitudes dos personagens homossexuais, inicialmente, discutiremos a biografia de Caio Fernando Abreu e a fábula de Pela Noite (1983).

\section{Caio Fernando Abreu e Pela Noite} (1983)

O escritor gaúcho Caio Fernando Abreu nasceu em Santiago, em 1948. Aos quinze anos sai da cidade e vai para um internato protestante americano em Porto Alegre (ABREU, 1983). Devido ao jornalismo, Abreu vai morar em São Paulo, onde trabalhou como redator e editor por quase toda sua vida e integrou a equipe de alguns importantes jornais e revistas do país. Em 1996, em decorrência de complicações da AIDS, Abreu falece (BESSA, 2006).

$\mathrm{Na}$ literatura, Abreu escreveu narrativa infanto-juvenil, crônicas, contos, novelas, romances e peças; e foi como contista que mais se destacou e ficou conhecido. 
A respeito de sua obra, dizia que, como ele próprio, ela também caminhava à margem da literatura brasileira, porque ele não conseguia se encaixar no campo das letras, principalmente devido à utilização, em seus textos, de temas conhecidos como malditos pela sociedade majoritária (BESSA, 2006).

É de acordo com a visão da sociedade dominante - machista e patriarcal - que a temática "maldita" pode ser identificada na novela Pela Noite (1983); em outras palavras, o tema central é a homoafetividade, algo rejeitado, mal visto e ignorado pela classe dominante.

A novela relata o reencontro de dois homossexuais que passaram a infância na mesma cidade, mas nunca tiveram contato nesse período. Certo dia eles se reencontram e marcam um encontro para o sábado seguinte à noite; o que ocorre no apartamento de um deles. Ambos os personagens utilizam nomes fictícios: Santiago e Pérsio; esses são escolhidos por eles mesmos e em nenhum momento são revelados seus reais nomes.

Após o breve encontro no apartamento de Pérsio, eles saem frequentando diversos locais, inclusive alguns de público gay. No decorrer da noite, eles começam a relembrar seu passado e a discutir sobre a homoafetividade, e assim surgem diversas complicações que são resolvidas somente no amanhecer, com os dois terminando juntos.

\section{Confrontos: a homoafetividade e A HEGEMONIA}

Neste tópico, analisaremos como os espaços determinam as atitudes dos personagens e também os momentos em que um dos personagens principais, Pérsio, se mostra em conflito não só com a sua homossexualidade mas, principalmente, com o fato de poder existir amor entre dois homens.

Logo no início do conto, Pérsio se apresenta como possuidor de um conflito interno a respeito de quem ele é: "Eu tenho uma sensação meio de amargura, de fracasso. Você me entende? Como se tivesse a obrigação de ter sido, ou tentado ser, outra pessoa." (ABREU, 1983, p.111). Percebe-se que o personagem vive um conflito, pois tem a sensação de fracassado, ou seja, ele acredita que deveria ter sido outra pessoa e não um homossexual. Portanto, é fato que Pérsio tem problemas com sua homossexualidade, e isso acontece porque a sociedade patriarcal elege o heterossexual como o modelo a ser seguido e valorizado, e, consequentemente, o fracasso do personagem é devido às regras que compõem o sistema social que o coloca na posição de marginalizado, "perverso", "pecador", "subjugado" e "inferiorizado".

Adiante, o mesmo personagem revela um pouco de sua infância e acaba explicando a origem de seu conflito:

[...] Sabe que quando eu saía na rua as meninas gritavam biiiiiiiiicha! Não, não era bicha. Nem veado. Acho que era maricas, qualquer coisa assim.[...] E eu nem era, porra, eu nem sabia de nada. Eu não entendia nada. Eu era superinocente, nunca tinha trepado. Só fui trepar aqui, já tinha quase vinte anos. E cheio de problemas, beijava de boca fechada.[...] Mas não vem ao caso, tudo superado. Ah, tão Maduro \& Equilibrado. Cinco anos de terapia, sob controle. (ABREU, 1983, p.153). 
Por meio desse outro excerto, podemos concluir que Pérsio, além de sofrer muito preconceito ainda jovem, também ficou traumatizado e teve de fazer terapia. Observa-se que a sociedade o tratou de forma tão injusta e o subjugou tanto que isso deixou marcas para toda sua vida, por isso se sente amargurado e fracassado. Esses excertos mostram claramente como a minoria homossexual é recriminada pelas leis sociais, em que tudo que foge ao padrão é discriminado.

É nesse clima entre se exporem como homossexuais ou não que os dois personagens principais acabam adotando nomes fictícios: "Você vai se chamar Santiago" (ABREU, 1983, p.114), e o dono do apartamento continua: "Pérsio, de agora em diante eu vou me chamar Pérsio" (ABREU, 1983, p.114). Com a nomeação, nota-se que eles não receberam só um novo nome, mas esconderam suas verdadeiras identidades e assumiram outra para justificar a relação homossexual: "Com um nome desses, você pode virar a noite impunemente [...] sem culpa alguma, rapaz" (ABREU, 1983, p. 118). Os fragmentos denotam que a escolha de outro nome é uma metáfora, a qual significa que na esfera social os homossexuais não podem revelar-se como realmente são, pois a heteronormatividade acaba "obrigando-os" a assumirem duas personalidades, ou seja, durante o dia ou no decorrer do trabalho, eles devem se apresentar como homens heterossexuais, de acordo com o padrão vigente, e à noite, ou às escuras, eles assumem a identidade homossexual - daí o título da novela - Pela Noite; é devido a todo esse preconceito existente na sociedade que muitos passam a vida inteira marginalizados:

[...] o homossexual é duplamente marginal. É marginal no sentido de estar, como a mulher, à margem do centro. Mas é marginal, ainda, no sentido conotativo do termo, na acepção de fora da lei, de pervertido, de imoral, de pecador. (THOMÉ, 2009, p.22).

Ao decorrer da trama, os dois personagens principais frequentam diversos locais, e em todas as situações eles estão conversando e raramente se envolvem com outras pessoas. Em um dado momento, após Santiago contar que teve um relacionamento homoafetivo que durou dez anos, Pérsio confessa: "Eu nunca consegui ficar mais do que um mês transando com a mesma pessoa" (ABREU, 1983, p.160). Essa afirmação de Pérsio mostra que ele, realmente, nunca conseguiu atingir uma relação sentimental amorosa longínqua e estabilizada até o presente, tanto que cita o espaço de tempo em que transava e não o tempo de afeto. Pouco depois, ele ainda argumenta que o amor entre dois homens se resume ao sexo, e o que o sexo anal é nojento, porque faz-se pelo mesmo canal em que se eliminam as fezes do corpo. Desta forma, esse personagem vê o relacionamento entre homens como algo repugnante (ABREU, 1983, p.164).

Vale lembrar que tanto Pérsio quanto Santiago assumem-se como homossexuais, o que fica explícito nas palavras:

$\mathrm{O}$ que você quer que eles pensem de nós, de mim, aqui, a teus pés? E em qualquer das hipóteses as mammas cutucarão seus maridos ruins de cama 
repetindo baixinho, escandalizadas, guarda, amore, questi belli ragazzi, Dio mio, veados. (ABREU, 1983, p.150).

Além disso, sabe-se também que Pérsio não simpatiza com o sexo feminino "Eu não gosto de mulher. Até já transei, mas não sinto nada" (ABREU, 1983, p.166), porém, esses fatores não o impedem de sentir asco pelo modo mais recorrente nas relações sexuais entre homossexuais masculinos: 0 coito anal.

Esse ponto de vista de Pérsio, de que o amor entre homens é nojento, constitui, na verdade, a visão da sociedade cristã e machista; pois é a hegemonia social que prega que qualquer manifestação homossexual é considerada perversa e nojenta. Pode-se dizer nojenta, pois a supremacia a vê como algo sujo, ilícito, de acordo com parâmetros religiosos e morais construídos a partir de ideologias dominantes até então. Durante séculos, o sexo anal foi chamado de sodomia, em alusão à cidade bíblica de Sodoma, na qual o magistério cristão, alegava que tal prática ocorria, sendo assim a cidade por Deus castigada (Gênesis, cap. 19), reforçando a ideia de ser considerado algo contrário à vontade divina. $O$ pesquisador brasileiro Luiz Mott (2010) considera que a sodomia homossexual sempre teria sido muito mais reprimida que a heterossexual (qualquer relação sexual que não levasse à procriação), por serem dois homens a desperdiçarem o esperma, indo contra os projetos expansionistas, tanto de judeus, como cristãos e muçulmanos, como por representarem um estilo de vida incompatível com o modelo de família patriarcal (MOTT, 2010).
Logo após seus questionamentos, Pérsio chega a uma conclusão sobre o indivíduo gay:

Pois parece assim. Uma maldição. Para sempre. Só acaba quando amputam os pés da moça. Quando você perde um pedaço? Quando você se anula? Quando você renuncia e nunca mais trepa? (ABREU, 1983, p.166).

Nesse fragmento vê-se a presença de outra metáfora a respeito de uma maldição dos homossexuais; é como se a soberania que determina as leis - tivesse amaldiçoado ou condenado todos os homossexuais, e eles só se livrariam dessa maldição se renunciassem ao sexo com outros homens. Na realidade, sabemos que é isso o que verdadeiramente acontece, pois, como afirma Thomé (2009), o homossexual é marginalizado, mas se ele deixar de ser o que é e se tornar um "heterossexual", ele entra em sintonia com o padrão e deixa de ser inferiorizado.

Santiago e Pérsio ainda discutiam sobre a homoafetividade entre homens, quando Pérsio comenta sobre o amor e sobre si:

Mas e isso que falavam, amor? Essa sua história, eu não conheço. Eu só tive vislumbres, parecia prometido, preparado. E nunca aconteceu. Eu nunca consegui, eu nunca fui capaz, deve ser culpa minha. Ah, que banal. Até que ponto as circunstâncias não me favoreceram, ou eu é que não favoreço as circunstâncias? (ABREU, 1983, p.166).

Nesse momento, Pérsio deixa transparecer que, na verdade, nunca conseguiu amar outro homem e, decepcionado, 
assume toda a culpa pelo fato. Após isso, Santiago argumenta que o amor vai além da higiene e do nojo e, segundo ele, isso é uma criação da sociedade burguesa e cristã (ABREU, 1983, p.168). Quando Santiago termina sua explanação sobre o amor, Pérsio se conscientiza do verdadeiro culpado pela sua incapacidade de amar: "O meu problema é um problema juvenil, de adolescente enrustido. Ou de burguesinho que fez a primeira comunhão e vai se sentir eternamente culpado com a possibilidade do prazer" (ABREU, 1983, p.169 - grifo nosso). Aqui Pérsio confessa que veio de uma família burguesa e que foi educado de acordo com o cristianismo. Temos, portanto, a certeza de que o que gera nele a dificuldade em amar outros homens e também de sentir prazer nas relações é a sua educação de acordo com a heteronormatividade. Assim, percebe-se mais uma vez que a sociedade cria regras discriminatórias para com as minorias homossexuais, transformando-os em pessoas naturalmente aptas a subverter moralmente a sociedade (COSTA, 1992, p.46).

Há na narrativa também outros contextos que deixam transparecer como o sistema majoritário influencia o comportamento dos homossexuais nas mais diversas situações. Neste caso, o espaço é algo importante de ser pontuado no decorrer da trama.

Pérsio e Santiago foram a uma pizzaria: "Daqui a umas seis quadras tem uma pizzaria absolutamente normal” (ABREU, 1983, p.145), e depois o narrador contextualiza mais esse espaço: "Santiago olhou em volta. Localizou três mocinhas feias na mesa ao lado e, mais além, um casal ente- diado [...] cheio de criancinhas barulhentas" (ABREU, 1983, p.149). A partir dessas falas, percebemos que a pizzaria é caracterizada como "normal" porque é um ambiente de público heterossexual, mostrando isso que até os próprios personagens gays têm (pré) conceito contra si, pois quando ele afirma que aquilo é normal, quer dizer que eles não são normais, uma imagem criada pela sociedade hegemônica.

Nesse espaço "normal" surge Carlinhos, um conhecido de Pérsio, o qual se comporta o mais polidamente possível: "Carlinhos curvou a cabeça. Fez um ar tardiamente polido de não-quero-interromper-nada-entre-vocês, apertou a mão de Santiago, levemente cúmplice, e foi saindo entre as mesas." (ABREU, 1983, p.163). Todo esse comportamento educado e tímido de Carlinhos entra em choque com as suas próprias atitudes que se estabelecerão num outro espaço, no bar Deer's, que é um local destinado ao público gay:

Não quero interromper nada. - Carlinhos estendeu a mão para os copos. - Posso dar um gole? [...] Desculpa eu ser indiscreto, longe de mim, mas. Vocês são caso? [...] Aliás, meu bem, me dá licença de dizer. De muito bom gosto, os dois. Umas gracinhas, uns gatinhos. Sabia que vocês são lindos? - Bebeu outro gole de vinho. E debruçou-se na mesa. - Ah, deixa de onda, qual é? Conta logo, vai. Vocês são mesmo caso? (ABREU, 1983, p.182).

Nesse momento fica nítido o contraste entre as atitudes de Carlinhos na pizzaria e no bar, ou seja, quando ele está num espaço 
de público hétero, tenta manter a imagem de um homem heterossexual, mas, a partir do momento que ele se encontra no "gueto" - bar - ele se sente livre para agir da forma que desejar. Costa (1992) discorre sobre os guetos:

O gueto é formado por um circuito de locais de encontro exclusivo de homossexuais, que vão de praias a pontos de prostituição masculina. Nesses locais, alguns extremamente sórdidos, os indivíduos gozam da "liberdade" que a discriminação permite. Mas, justamente por tratar-se de uma liberdade vigiada e concedida, carrega todas as sequelas do preconceito. Os sujeitos sabem, mesmo quando não explicitam, que a liberdade vivida no gueto é precária e, num certo sentido, artificial. (COSTA, 1992, p.96).

Observa-se que a classe homossexual é vista com muito preconceito, já que nem nesses lugares restritos tem-se real liberdade; a busca por locais ou situações privadas de preconceito é um objetivo utópico em relação à sociedade vigente.

No final da novela, o foco volta para os personagens; e Pérsio mostra certa superação a respeito de sua incapacidade de amar, o que fica claro na seguinte fala direcionada a Santiago: "Eu gosto de você, eu gosto tanto de você, garoto. Me dá outra chance. Me deixa guiar a nossa noite." (ABREU, 1983, p.187). Nessa afirmação, nota-se que o personagem conseguiu transgredir todas as "leis" socialmente impostas e todo o preconceito existente e que, portanto, está começando a amar um outro igual.
Nas últimas linhas, o amor entre eles é concretizado com as palavras: "Provaram um do outro, no colo da manhã. E viram que era bom." (ABREU, 1983, p.210). Esse término mostra que a homoafetividade, apesar de ser um obstáculo na vida de muitos homossexuais, é uma conquista possível, ou seja, ela pode ser atingida por todos que realmente desejam e acreditam no amor entre homens ou no amor entre mulheres e seus iguais.

\section{ConClusão}

Concluímos que Pérsio, por ser traumatizado pela discriminação e pelo preconceito da sociedade, possui problemas em aceitar a homoafetividade, pois inicialmente ele se mostra completamente contrário à possibilidade de haver o sentimento do amor entre dois homens; entretanto, com o desenlace da trama, ele acaba se apaixonando pelo amigo Santiago, e ambos vivem e passam a acreditar nesse amor como algo possível de ser realizado.

Além disso, pode-se inferir que o sistema social vigente realmente trata os homossexuais com muito desprezo e discriminação, e um exemplo disso é a formação de guetos, locais onde os gays tentam buscar uma liberdade de expressão, mas ainda assim, o fato desses lugares serem à parte do restante da sociedade, só ratifica a existência da discriminação e do preconceito.

\section{REFERÊNCIAS}

ABREU, Caio Fernando. Triângulo das águas. Rio de Janeiro: Nova Fronteira, 1983. 
BESSA, Marcelo Secron. Melhores contos: Caio Fernando Abreu. São Paulo: Global, 2006. COSTA, Jurandir Freire. A inocência e o vício: estudos sobre o homoerotismo. 3 ed. Rio de Janeiro: Relume-Dumará, 1992.

FOUCAULT, Michel. Um diálogo sobre os prazeres do sexo. BARRETO, Jorge Lima; CUPERTINO, Cristina Guimarães (Trad.), São Paulo: Landy, 2000.

LOURO, Guacira Lopes. Teoria queer: uma política pós-identitária para a educação. Revista Estudos Feministas, Florianópolis, v. 9, n. 2, p. 541-553, 2001.

MISKOLCI, Richard. A teoria queer e a sociologia: o desafio de uma analítica da normatização. Sociologias, Porto Alegre, v. 11, n. 21, p. 150-182, jan./jan. 2009.

MOOT, Luiz. Revolução homossexual: o poder de um mito. Disponivel em: <http:// culturagay.planetaclix.pt/>. Acesso em: 21 jul. 2010.

PARADISO, Silvio Ruiz; PELINCER, Edilaine. Estudos Culturais: o boom teórico para as literaturas pós-modernas [apostila]. In: SEMINÁRIO INTERDISCIPLINAR DE EDUCAÇÃO, 5, 2007, Maringá. Mini curso. Maringá: Centro Universitário de Maringá, 2007. p.1-14.

THOMÉ, Ricardo. Eros proibido: as ideologias em torno da questão homoerótica na literatura brasileira. Rio de Janeiro: Nova Razão Cultural Editora, 2009.

Recebido para publicação em 29 out. 2010. Aceito para publicação em 19 jan. 2011. 